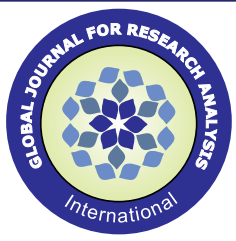

\title{
CLINICAL STUDY ON FOURNIER'S GANGRENE
}

\section{Dr. Y. Sarath Chandu

\section{KEYWORDS :}

\section{INTRODUCTION}

Fournier's gangrene is a surgical emergency with a high mortality rate. Fournier's gangrene (FG) is an acute, rapidly progressive, and potentially fatal, infective necrotizing fasciitis affecting the external genitalia, perineal or perianal regions, which commonly affects men, but can also occur in women and children. Although Jean Alfred gave this condition its eponymous name in 1883, it was first described by Baurienne in 1764 . FG is relatively rare, with an estimated overall incidence of $1.6 / 100000$ males $^{3}$. Many patients with Fournier's gangrene have either medical or surgical conditions, which are the predisposing factors to FG or its more severe or fatal course.

\section{AIM OF THE STUDY}

To study the aetiology, microbiology, predisposing factors, management and outcomes in our setting.

\section{METHODOLOGY}

30 patients who presented to the General surgery department NARAYANA MEDICAL COLLEGE, NELLORE during the period from January 2019 to January 2020 form the subjects of the study. This study is a prospective observational study. History, clinical examination, investigations, treatment details recorded and analyzed for the study purpose.

\section{RESULTS}

Table No: 1 Age distribution

\begin{tabular}{|c|c|c|}
\hline Age Group & Number of cases(n=30) & Percentage \\
\hline$<20$ & 1 & 3 \\
\hline $21-30$ & 2 & 7 \\
\hline $31-40$ & 3 & 10 \\
\hline $41-50$ & 5 & 16 \\
\hline $51-60$ & 15 & 50 \\
\hline$>60$ & 4 & 14 \\
\hline
\end{tabular}

Table No 2 Etiological Agent

\begin{tabular}{|c|c|c|}
\hline Organism & Number of cases(n=30) & Percentage \\
\hline E.coli & 16 & 53 \\
\hline Streptococcus & 15 & 50 \\
\hline Staphylococcus & 10 & 33 \\
\hline Bacteroides & 9 & 30 \\
\hline Proteus & 4 & 13 \\
\hline Pseudomonas & 2 & 7 \\
\hline Klebsiella & 5 & 17 \\
\hline
\end{tabular}

Most of the culture aspirates are polymicrobial (80\%). Only $14 \%$ are monomicrobial, and $6 \%$ are sterile aspirates.

Table No:3 Aetiological factors

\begin{tabular}{|c|c|c|}
\hline Factor & Number of cases(n=30) & Percentage \\
\hline Colorectal disease & 9 & 30 \\
\hline Genitourinary disease & 7 & 23 \\
\hline Hernia repair & 2 & 7 \\
\hline Trauma & 6 & 20 \\
\hline Idiopathic & 5 & 17 \\
\hline Others & 1 & 3 \\
\hline
\end{tabular}

Table No:4 Comorbid conditions

\begin{tabular}{|c|c|c|}
\hline Comorbidity & Number of cases $(\mathbf{n}=\mathbf{3 0})$ & Percentage \\
\hline Diabetes & 14 & 47 \\
\hline Chronic alcoholic & 6 & 20 \\
\hline Renal failure & 4 & 13 \\
\hline Immunosuppression & 5 & 17 \\
\hline No comorbidity & 1 & 3 \\
\hline
\end{tabular}

Table No:5 Extent of the disease

\begin{tabular}{|c|c|c|}
\hline Extent & Number of cases $(\mathbf{n}=\mathbf{3 0})$ & Percentage \\
\hline Genitalia only & 16 & 53 \\
\hline $\begin{array}{c}\text { Genitalia + Perineum } \\
\begin{array}{c}\text { Genitalia + Perineum } \\
\text { +abdominal wall }\end{array}\end{array}$ & 10 & 34 \\
\hline
\end{tabular}

All 30 patients underwent surgical debridement, out of which five patients required multiple debridements.

Table No:6 Reconstructive Procedures

\begin{tabular}{|c|c|c|}
\hline Procedure & Number of cases $(\mathbf{n}=30)$ & Percentage \\
\hline Primary closure & 14 & 47 \\
\hline Skin grafting & 5 & 17 \\
\hline Local flap & 1 & 3 \\
\hline Not required & 10 & 34 \\
\hline
\end{tabular}

Out of 30 , five (17\%) patients expired, and the remaining $25(83 \%)$ were healed entirely and sent home.

\section{DISCUSSION}

In our study, the majority of patients of FG are in $5^{\text {th }}$ decade, which is in coordinance with other studies ${ }^{2-8}$.

The principal etiological agents in our study are E.coli(53\%) and Streptococcus (50\%), which is same as Mallikarjunl ${ }^{1}$ et al., smith $^{2}$ et al. Morpurgo et al., Ayan ${ }^{4}$ et al., Sockkalingam ${ }^{6}$ et al. Singh ${ }^{7}$ et al.

$80 \%$ of culture aspirates are polymicrobial, which coincides with other studies.

In our study, colorectal (30\%) and genitourinary diseases (23\%) are the main aetiological factors of the disease. Similar findings observed in Mallikarjunal ${ }^{1}$ et al., which is $20-50 \%$ in gastrointestinal and $20-40 \%$ in genitourinary disorders.

$14(47 \%)$ cases in our study are diabetic, which is the main comorbid condition associated with Fournier's gangrene. Similarly, in Sockkalingam ${ }^{6}$ et al., $38.2 \%$ of patients had diabetes, followed by chronic alcoholism and immunosuppression.

In our study, the majority of the patients(53\%) presented with disease confined to genitalia only similar to Tahmaz5 et al.. Perineum, abdominal wall also involved along with genitalia in $4(13 \%)$ patients.

Primary closure was done in 14(47\%) patients; skin grafting 
was done in $5(17 \%)$ patients and reconstructive procedure, not at all required in 10(34\%) cases. In the study of Sockkalingam ${ }^{6}$, 13 patients out of 34 managed by primary closure for scrotal skin defect, one needed split skin grafting, and two required local skin flap.

Mortality was seen in 5(17\%) patients in this study, a similar pattern seen in Sockkalingam $4(11.8 \%)$ cases. Mortality was slightly less in Sorensen ${ }^{3}$ et al.(7.5\%). According to Benjelloun ${ }^{10}$ et al., the mortality rate ranges from $4 \%$ to $80 \%$.

\section{CONCLUSION}

Although FG is a relatively rare disease, it is still prevalent in the Indian population. Diabetes is the most common comorbid condition seen in FG patients, followed by chronic alcoholism and immunosuppression. FG is a polymicrobial infection with E.coli, Streptococcus and staphylococcus being the commonest organisms. Local extension and mortality can be prevented with aggressive antibiotics and early surgical debridement. Reconstructive procedures can be done whenever required.

\section{REFERENCES}

1. Mallikarjuna, M. N., Vijayakumar, A., Patil, V. S. \& Shivswamy, B. S. Fournier's Gangrene: Current Practices. ISRN Surg. 2012, 942437, (2012).

2. Smith, G. L., Bunker, C. B. \& Dinneen, M. D. Fournier's gangrene. Br. J. Urol. 81, 347-355 (1998).

3. Sorensen, M. D. et al. Fournier's Gangrene: population-based epidemiology and outcomes. J. Urol. 181, 2120-2126 (2009).

4. Ayan, F. et al. Fournier's gangrene: a retrospective clinical study on forty-one patients. ANZJ. Surg. 75, 1055-1058 (2005)

5. Tahmaz, L., Erdemir, F., Kibar, Y., Cosar, A. \& Yalcýn, O. Fournier's gangrene: report of thirty-three cases and a review of the literature. Int. J. Urol. Off. J. Jpn. Urol. Assoc. 13, 960-967 (2006).

6. Sockkalingam, V. S., Subburayan, E., Velu, E., Rajashekar, S. T. \& Swamy, A. M. Fournier's gangrene: a prospective study of 34 patients in South Indian population and treatment strategies. Pan Afr. Med. J. 31, (2018).

7. Singh, A., Ahmed, K., Aydin, A., Khan, M. S. \& Dasgupta, P. Fournier's gangrene. A clinical review. Arch. Ital. Urol. Androl. Organo Uff. Soc. Ital. Ecogr. Urol. ENefrol. 88, 157-164 (2016).

8. Wróblewska, M. et al. Fournier's gangrene--current concepts. Pol. J. Microbiol. 63, 267-273 (2014)

9. Morpurgo, E. \& Galandiuk, S. Fournier's gangrene. Surg. Clin. North Am. 82, 1213-1224 (2002).

10. Benjelloun, E. B. et al. Fournier's gangrene: our experience with 50 patients and analysis of factors affecting mortality. World J. Emerg. Surg. WJES 8, 13, (2013). 